\title{
Lea Tochtermann
}

\section{Sukzessionsschutz im Recht des Geistigen Eigentums}

Eine Untersuchung unter besonderer Berücksichtigung internationalprivatrechtlicher Zusammenhänge

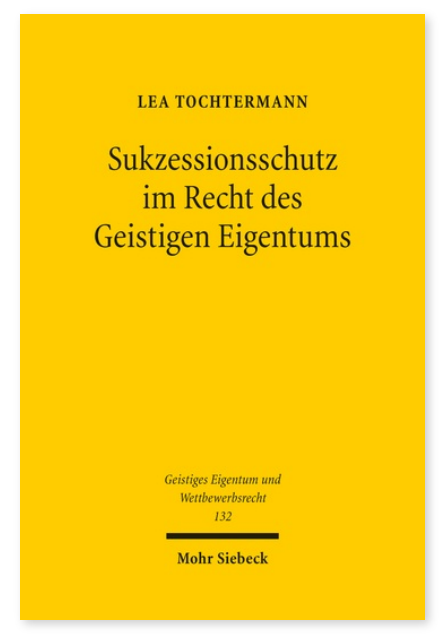

2018. XXIII, 371 Seiten. GEuWR 132

ISBN 978-3-16-156160-3

DOI 10.1628/978-3-16-156160-3

eBook PDF $89,00 €$

ISBN 978-3-16-154875-8

fadengeheftete Broschur $89,00 €$
Der Sukzessionsschutz im Recht des Geistigen Eigentums schützt bereits erteilte Lizenzen im Fall der Übertragung des Schutzrechts oder der Erteilung einer weiteren Lizenz. Während sich die Anordnung des Sukzessionsschutzes in allen Schutzgesetzen und Verordnungen über einheitliche Rechtstitel findet, werden die Wirkungen nirgends näher dargelegt. In einem schutzrechtsübergreifenden Ansatz zeigt Lea Tochtermann systematisch die Grundkonstellationen des Sukzessionsschutzes auf und analysiert die Wirkungen der gesetzlichen Anordnung. Neben den Konsequenzen bei Zugrundelegung der herrschenden Meinung untersucht sie auch die Leistungsfähigkeit des Modells, welches die Lizenz als verdinglichte Obligation liest. Der praktischen Bedeutung des Sukzessionsschutzes im grenzüberschreitenden Rechtsverkehr wird durch die Fortentwicklung der gefundenen Lösungsansätze auf international-privatrechtlicher Ebene Rechnung getragen.

Lea Tochtermann Geboren 1983; Studium der Rechtswissenschaften in Heidelberg und Paris; Referendariat im Justizdienst des Landes Rheinland-Pfalz mit Wahlstation am Gerichtshof der Europäischen Union in Luxemburg; Wissenschaftliche Mitarbeiterin an der Universität Mannheim und in einer Rechtsanwaltssozietät in Frankfurt a.M.; 2016 Promotion; seit 2016 Juniorprofessorin für Bürgerliches Recht und Europäisches Patentrecht an der Universität Mannheim.
Jetzt bestellen:

https://mohrsiebeck.com/buch/sukzessionsschutz-im-recht-des-geistigen-eigentums-9783161561603?no_cache=1 order@mohrsiebeck.com

Telefon: +49 (0)7071-923-17

Telefax: +49 (0)7071-51104 